Değirmenci, T. ve Yavuz, H. (2021). "Emisyon Azaltım Sorumluluğu Olan BM Ülkelerinde Hava Kirliliği, Sağlık Harcamaları ve Ekonomik Büyüme ilişkisi”, Eskişehir Osmangazi Üniversitesi iỉBF Dergisi, 16(3), 856 - 872.

Doi: 10.17153/oguiibf.976646

Başvuru: 30.07.2021 Kabul: 14.09.2021

Araştırma Makalesi/Research Article

\title{
Emisyon Azaltım Sorumluluğu Olan BM Ülkelerinde Hava Kirliliği, Sağlık Harcamaları ve Ekonomik Büyüme İlişkisi
}

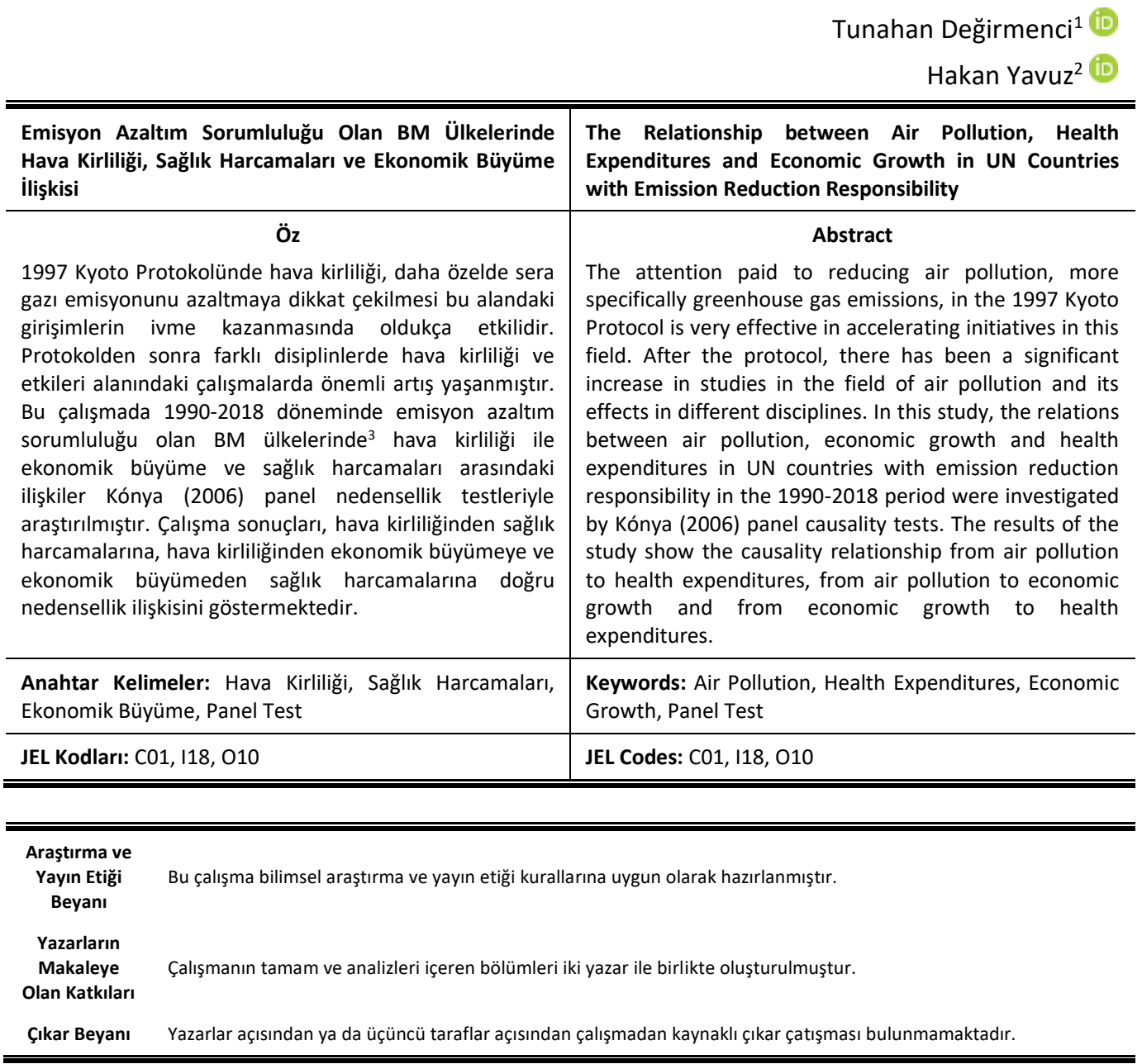

\footnotetext{
${ }^{1}$ Arş. Gör., Sakarya Üniversitesi Siyasal Bilgiler Fakültesi Maliye Bölümü, tunahandegirmenci@sakarya.edu.tr

2 Doç. Dr., Sakarya Üniversitesi Siyasal Bilgiler Fakültesi Maliye Bölümü, hyavuz@sakarya.edu.tr

${ }^{3}$ Bu kapsamda; ABD, Birleşik Krallık, Danimarka, Finlandiya, Fransa, Hollanda, İrlanda, İsveç, İsviçre, İtalya, İzlanda, Kanada, Norveç, Portekiz ve Yunanistan ülkeleri ele alınmıştır.
} 


\section{Giriş}

Hava kirliliği ve daha da özelde sera gazı emisyonlarının artmasında birçok faktörün etkisi vardır. Nüfus artışı, sanayileşme/endüstriyel faaliyetler, enerji ihtiyacı ve motorlu taşıt kullanımındaki artış ve kentleşme/şehirleşmenin getirdiği ihtiyaç ön plana çıkan faktörlerdir. Sera gazlarının artması iklim değişikliğini tetikleyerek; insan sağlığı, toplum, ekonomi ve çevresel sürdürülebilirlik üzerinde ciddi bir tehlike oluşturmaktadır. Dünya Sağlık Örgütü (WHO) verileri, hava kirliliğinden dünyanın tüm bölgelerinin etkilendiğini göstermektedir. Özellikle düşük gelirli ülkelerde şehirlerde yaşayanlar, hava kirliliğinden daha fazla etkilenmektedir. Hava kalitesi azaldıkça kalp hastalığı, akciğer kanseri ve astım dâhil birçok kronik ve akut solunum hastalıkları artmaktadır. WHO verilerine göre, dünyada 10 insandan 9'u yüksek düzeyde kirletici hava solumakta ve her yıl yaklaşık 7 milyon kişi hava kirliliği nedeniyle hayatını kaybetmektedir (WHO, 2021).

Dünyada hava kirliliğinin artışı 20. yüzyılın ikinci yarısından sonra dillendirilmeye başlansa da 1980'lerden sonra çok taraflı anlaşmalarla bu probleme yönelik çözüm arayışları da artmıştır. 1990'lı yıllarda Birleşmiş Milletler (BM) öncülüğünde gerçekleştirilen toplantılar problemin esaslı bir şekilde kabul edilmesine ve çözümüne yönelik yeni tartışmaları da beraberinde getirmiştir. Bu süreçte özellikle fosil yakıtların kullanılmasıyla ortaya çıkan sera gazı emisyonlarını azaltma çabası, sonraki toplantıların gündem konusu olmuş ve birçok araştırmada da inceleme konusu yapılmıştır. Bu bağlamda ekonomik büyümeyle ilişkilendirilen ve fosil yakıtların kullanılması sonucu oluşan emisyonların, küresel iklim değişikliğine neden olduğu ve sonuç olarak insan sağlığını olumsuz etkilediği söylenebilir. Bu durum, birçok araştırmacının ve politika yapıcıların odak noktası haline gelmiştir.

1997 Kyoto Protokolünden sonra Birleşmiş Milletler EK-II ülkelerinin sera gazı emisyon değerlerini azaltmak zorunda kalması, özellikle enerji alanında daha temiz üretim kaynaklarını zorunlu hale getirmiştir. Bununla birlikte, birçok ülke daha temiz ve çevreci bir üretim modeli arayışına girmiştir. Süreç boyunca yeterli dönüşümü sağlayabilen ülkeler yıllar itibariyle emisyon değerlerini azaltabilirken, sağlayamayan ülkeler ise azaltamamış veya azaltım miktarı yeterli seviyeye ulaşmamıştır. Çünkü azaltımın yüksek bir ekonomik maliyeti bulunmaktadır. Bu nedenle hava kirliliği araştırmalarının önemli bir kısmı ekonomik büyüme veya gelişme ile de ilişkilendirilmektedir. Bazı araştırmalarda ise hava kirliliğinin insan sağlığı üzerindeki etkisi ele alınmakta ve hava kirliliği-sağlık harcamaları ilişki incelenmektedir.

Hava kirliliğinin insan sağlığı üzerindeki olumsuz etkileriyle birlikte, son yıllarda ekonomik büyüme, çevresel bozulma ve sağlık harcamaları arasındaki ilişki literatürde giderek artan bir ilgi görmektedir (Chaabouni, Zghidi ve Mbarek 2016; Wang, Hsueh, Li ve Wu 2019). Çevresel kalitenin düşmesi ve kirliliğin artması, hükümetlerin sağlık harcamalarına daha fazla bütçe ayırmasına neden olmaktadır. Sağlık harcamalarının artması ise ilgili ülke ekonomilerini doğrudan etkileyebilmektedir (Khoshnevis Yazdi ve Khanalizadeh, 2017). Bir anlamda Çevresel Kuznets Hipotezine sağlık harcamalarının eklendiği bu literatürde kirlilik göstergesi olarak çoğunlukla karbon emisyonunun kullanıldığı görülmektedir. Fakat 6. Birleşmiş Milletler Çevre Raporunda karbon emisyonunun sağlık üzerinde dolaylı bir etkisi olduğu, partikül maddenin ise insan sağlığı üzerinde doğrudan bir etkiye sahip olduğuna dikkat çekilmiştir (Dickerson, Guerreiro, Keating, Nzioka, Chung, Reis ve Hurley 2019). BM çevre raporu tanımlamasına göre, partikül madde (PM) kısaca, havada asılı kalan küçük katı parçacıklar veya sıvı damlacıklardır. Dünya çapında sağlık üzerinde tehdit oluşturan en büyük etken partikül maddelerdir. Partikül maddeler dünya nüfusunun büyük bir bölümünü diğer kirleticilerden 
daha fazla etkilemektedir. Bu maddelere maruz kalan insanlar solunum ve kalp-damar hastalık riskiyle karşı karşıya kalmaktadırlar (OECD Data, 2020). Nitekim 6. Birleşmiş Milletler çevre raporuna göre, partikül maddeler 2016 yılında yaklaşık 4 milyon erken ölüme sebebiyet vermiştir. Bu yüzden raporda, ortamdaki hava kirliliğini artırarak sağlık üzerinde ciddi olumsuz etkilere neden olmasından dolayı partikül maddelerin azaltılması gerektiği belirtilmiştir (Lucas, Hedden, Vuuren, Calvin, Chung, Harfoot ve Hurley 2019). Bu noktadan hareketle, bu çalışmada hava kirliliği göstergesi olarak insan sağlığını doğrudan etkilediği belirtilen partikül madde verisi kullanılmıştır.

Bu çalışmanın amacı 1990-2018 dönemi için EK-II ülkeleri arasından 15 OECD ülkesinde hava kirliliği, sağlık harcamaları, ekonomik büyüme ilişkisini araştırmaktır. Birleşmiş Milletler EK-II ülkeleri sera gazı emisyon değerlerini azaltmak için zorunlu yükümlülük altındadırlar. Bu yüzden çalışmadaki ülke grubu, Birleşmiş Milletler EK-II ülkeleri arasından seçilmiştir. . Literatürde hava kirliliği, sağlık harcamaları, ekonomik büyüme ilişkisini ele alan araştırmalar azınlıkta olmakla birlikte, bu çalışmaların birçoğunda hava kirliliği göstergesi olarak karbon emisyonu dikkate alınmaktadır. Ayrıca çalışmalar daha çok iki gösterge arasındaki ilişkiyi incelemektedir. Çalışmanın bu hususlarda diğer çalışmalardan ayrışarak literatüre katkı sağlaması beklenmektedir.

\section{Literatür Özeti}

Literatürde çoğunlukla hava kirliliği, ekonomik büyüme ve sağlık harcamaları arasındaki ikili ilişkiler incelenmiştir. Bu literatür başlıca üç grupta incelenebilir. En yaygın olan birinci gruptaki ampirik çalışmalar, hava kirliliği ve ekonomik büyüme ilişkisi üzerinedir. Bu ilişki genellikle Grossman ve Krueger (1991) tarafından öne sürülen Çevresel Kuznets Eğrisi (ÇKE) hipotezi kapsamında incelenmektedir. ÇKE, nüfusa oranlanmış milli gelir (kişi başına GSYiH) ile çevre kalitesi ilişkisini ters $U$ şeklinde gösteren bir eğridir. Bu hipoteze göre, ekonomiler ilk aşamada milli gelirini artırırken çevreye zarar verme eğilimindedir. Daha sonra belirli bir seviyeye ulaşıldığında milli gelir ile çevresel kalite birlikte artmaya başlar. Fakat, kişi başına düşen milli gelir ile çevre kirliliği ilişkisi üzerine yapılan ampirik çalışmalar net bir sonuç göstermemektedir. Wang, Zhang, Kubota, Zhu ve Lu (2015), Al-Mulali, Weng-Wai, Sheau-Ting ve Mohammed (2015), Wu, Zheng, Zhe, Xie ve Song (2018), Destek, Ulucak ve Dogan (2018), Destek ve Sarkodie (2019) ile Hassan, Xia, Khan ve Shah (2019) ÇKE hipotezini reddederken; Zhu, You ve Zeng (2012), Farhani ve Ozturk (2015), Dogan ve Turkekul (2016), Abdallh ve Abugamos (2017), Amri, Zaied ve Lahouel (2019), Destek ve Sinha (2020) ile Pata, U. K. ve Aydın, M. (2020) ÇKE hipotezini kabul etmektedir. Bununla birlikte bu çalışmaların birçoğunda, ekonomik büyüme ve çevre kirliliği arasında eşbütünleşme ilişkisi olduğu kanıtlanmıştır. Ayrıca Hassan vd. (2019), 1971-2014 yılları verileriyle Pakistan'da ekonomik büyüme ve çevre kirliliği arasındaki nedensellik ilişkisini VECM Granger nedensellik testleriyle araştırmışlardır. Çalışmanın sonuçlarına göre değişkenlere ait herhangi bir nedensellik ilişkisi bulunmamıştır. Quyang vd. (2019) ise çalışmalarında 30 OECD ülkesinde hava kirliliği (PM2.5) ile ekonomik büyüme arasındaki ilişkiyi 1998-2015 yıllarına ait verilerle incelemişlerdir. Çalışma sonuçları, ekonomik büyüme hava kirliliğiyle \%1 düzeyinde negatif ilişkilidir. Ekonomik büyüme ile hava kirliliği arasındaki ilişkiye yönelik literatür genel olarak değerlendirildiğinde her ne kadar iki değişken arasında güçlü bir ilişki bulunsa da partikül maddeyi azaltmak için tek faktörün gelir olmadığı, bunun dışında nüfus, kentleşme, trafik yoğunluğu ve endüstriyel yapı gibi faktörlerin PM2.5 üzerinde etkili olduğu söylenebilir (Cheng vd. 2010; Han vd. 2014; Wang vd. 2017; Han ve Sun 2019). 
İkinci gruptaki ampirik çalışmalar, ekonomik büyüme ve sağlık harcamaları arasındaki ilişkiye odaklanmaktadır. Bu çalışmalar genellikle, sağlık hizmetlerinin gelir esnekliğinin ölçümü ile sağlık hizmetlerinin sunumu ve finansmanına ilişkin politika önerilerini içermektedir. Sağılı harcamaları ile büyüme arasındaki ikili ilişkiyi araştıran çalışmalardan bazıları şu şekildedir: Çetin ve Ecevit (2010) çalışmalarında, 15 OECD ülkesi için ekonomik büyüme ile sağlık harcaması ilişkisini panel veriyle 1990-2006 dönemi özelinde araştırmışlardır. Çalışma sonuçları incelenen değişkenler arasında anlamlı bir ilişki olmadığını göstermektedir. Mehrara ve Musai (2011), çalışmalarında İran için 1970-2008 döneminde sağlık harcamaları ve GSYiH arasındaki ilişkiyi Gregory-Hansen eşbütünleşme yöntemi ve Granger nedensellik testinden yararlanarak incelemişlerdir. Çalışma sonuçları, değişkenlere ait uzun dönemli bir ilişki olduğunu göstermektedir. Ayrıca GSYiH'dan sağlık harcamalarına doğru tek yönlü bir nedensellik ilişkisi bulunmuştur. Bakare ve Samni (2011) ise Nijerya için ekonomik büyüme ve sağlık harcamaları arasındaki ilişkiyi en küçük kareler çoklu regresyon yöntemiyle incelemişlerdir. Çalışma sonuçları iki değişken arasında pozitif ve istatistiki olarak anlamlı bir ilişki olduğunu göstermektedir. Halıcl-Tülüce vd. (2016), 1995-2015 dönemi için 25 yüksek gelirli ülkede ve 1997-2009 dönemi için 19 düşük gelirli ülkede sağlık harcamaları ve ekonomik büyüme arasındaki ilişkiyi dinamik panel veri analiziyle araştırmışlardır. Çalışmanın sonuçları, uzun dönemde büyümeden sağlık harcamalarına doğru bir ilişki bulunurken, kısa dönemde sağlık harcamaları ile büyüme arasında karşılıklı olarak nedensellik ilişkisi bulunmuştur. Öte yandan çalışmada, kamu sağlık harcamalarının ekonomik büyüme üzerinde negatif, anlamlı bir etki gösterdiği ortaya çıkarılmıştır. Türkiye için Atılgan, Kılıç ve Ertuğrul (2017) çalışmalarında 1975-2013 dönemi özelinde sağlık alanına yönelik harcamaların büyüme üzerindeki etkisini ARDL sınır testi yaklaşımıyla araştırmışlardır. Çalışmanın bulgularına göre, sağlık harcamalarının \%1'lik artışı büyümeyi \%0,434 oranında artırmaktadır. Piabuo ve Tieguhong (2017) ise, 1995-2015 dönemi için 11 Afrika ülkesinde sağlık harcamaları ile büyüme ilişkisini OLS, FMOLS ve DOLS yöntemiyle analiz etmişlerdir. Çalışma bulgularına göre sağlık harcamaları büyüme üzerinde pozitif, anlamlı bir etkiye sahiptir. Dinçer ve Yüksel (2019) ise çalışmalarında, 1996-2016 dönemi için E7 ülkelerinde ekonomik büyüme ile kamu sağlık harcamaları ve özel sağlık harcamaları arasındaki ilişkiyi Pedroni panel eşbütünleşme yöntemiyle incelemişler. Çalışma bulgularına göre büyüme ve kamu sağlık harcamalarına ait uzun dönemli bir ilişki bulunurken, büyüme ile özel kamu harcamaları arasında ilişki bulunmamıştır. Bununla birlikte sağlık harcamalarından ekonomik büyümeye doğru herhangi bir nedensellik ilişkisi bulunmamaktadır.

Üçüncü gruptaki ampirik çalışmalar ise, çevre kirliliği ve sağlık harcamaları arasındaki ilişkiyi incelemektedir. Bu değişkenlerin bulunduğu çalışmaların birçoğunda ek olarak ekonomik büyüme, gelir düzeyi ve kalkınma göstergeleri kullanılmıştır. Sadece çevre kirliliği ve sağlık harcamalarını analiz eden çalışmalar azınlıktadır. Bu çalışmalardan bazıları aşağıdaki gibidir: Yazdi, Zahra ve Nikos (2014) çalışmalarında İran için 1967-2010 döneminde sağılık harcamaları ile çevre kirliliği arasındaki ilişkiyi ARDL yaklaşımı ile analiz etmişlerdir. Çalışma sonuçlarına göre, çevre kirliliğini temsilen kullanılan kükürt oksit ile karbon monoksit emisyonlarıyla sağlık alanındaki harcamalar arasında anlamlı bir ilişki bulunmaktadır. Hao, Liu, Lu, Huang ve Zhao (2018) ise çalışmalarında, 1998-2015 verilerini kullanarak Çin vilayetlerinde çevre kirliliği ile sağlık harcamaları arasındaki ilişkiyi genelleştirilmiş momentler yöntemiyle (GMM) incelemişlerdir. Çalışma sonuçları, çevre kirliliğinin sağlık harcamalarını artırdığını göstermektedir. Batı Afrika Ülkeleri Ekonomik Topluluğuna ait ülkeler için Alimi, Ajide ve Isola (2019) çalışmalarında 1995-2014 dönemi verilerini kullanarak çevre kirliliği ile sağlık 
harcamaları arasındaki ilişkiyi genelleştirilmiş momentler yöntemiyle (GMM) incelemişlerdir. Çalışma sonuçlarına göre, çevre kirliliğinin hem kamu hem de özel sağlık harcamaları üzerinde istatistiksel olarak pozitif, anlamlı bir etkisi bulunmaktadır. 178 ülke için yapılan çalışmada Apergis, Bhattacharya ve Hadhri (2020) 1995-2017 yılları verilerini kullanarak sağlık harcamalarıyla çevre kirliliği kapsamındaki ilişkiyi incelemişlerdir. Çalışmada bu ülkeler dört ayrı gelir grubuna ayrılmıştır. Çalışma sonuçlarına göre, dört ülke grubu için de milli gelirin sağlık harcamalarını artırdığı görülmüştür. Ayrıca, çevre kirliliğindeki \%1'lik bir artış, sağlık harcamalarını panelde $\% 2,5$ ve bu dört gelir grubunda sırasıyla $\% 2,9, \% 1,2, \% 2,3$ ve \%2,6 artırmaktadır.

Çevre kirliliği, sağlık harcamaları ve büyüme ilişkisini beraber ele alan çalışmalardan bazıları ise şu şekildedir: 51 ülkeyi kapsayan çalışmalarında Chaabouni vd. (2016), 1995-2013 dönemi verileriyle çevre kirliliği ve sağlık harcaması ile ekonomik büyüme arasındaki ilişkiyi dinamik eşzamanlı denklem modeliyle incelemişlerdir. Çalışma sonuçları panel için, çevre kirliliği ile ekonomik büyüme ve sağıık harcamalarıyla büyüme arasında karşılıklı nedensellik ilişkisini göstermektedir. Ayrıca düşük gelir grubundaki ülkeler hariç diğer ülkelerde çevresel kirlilikten sağlık harcamalarına nedensellik ilişkisi bulunmuştur. Zaidi ve Saidi (2018), Sahra-altı Afrika ülkelerinde 1990-2015 dönemi için hava kirliliği, sağlık harcamaları ile büyüme ilişkisini ARDL ve VECM Granger nedensellik testiyle incelemişlerdir. Çalışmanın sonuçlarına göre, büyümenin sağlık harcamaları üzerinde olumlu bir etkiye sahip olduğu görülürken, hava kirliliğinin sağlık harcamaları üzerinde olumsuz etkiye sahip olduğu görülmüştür. Öte yandan sağlık harcamalarından büyümeye bir ilişki tespit edilirken, $\mathrm{CO} 2$ emisyonu ile büyüme ve sağlık harcaması ile CO2 emisyonu arasında karşılıklı nedensellik tespit edilmiştir. Dumrul (2019) ise çalışmasında 2000-2014 döneminde ASEAN-5 ülkeleri için çevre kirliliğinin ve büyümenin sağlık alanında yapılan harcamalar üzerindeki etkisini Pedroni, Kao ve panel FMOLS eşbütünleşme yöntemi ile araştırmıştır. Çalışmanın sonuçlarına göre, çevre kirliliği, sağlık harcamaları ile büyüme arasında uzun dönemli ilişki bulunmuştur. Ek olarak çalışmada, çevre kirliliği ile büyümenin sağlık harcamalarını artırdığı tespit edilmiştir. 21 OECD ülkesi için yapılan çalışmada Şahin ve Durmuş (2019) 1990-2014 dönemindeki verileri kullanarak çevresel kirlilik, büyüme ve sağlık harcaması arasındaki ilişkiyi Westerlund ve Edgerton eşbütünleşme ve Emirmahmutoğlu-Köse nedensellik yöntemi ile incelemişlerdir. Çalışma sonuçları, Finlandiya, İspanya, İsveç, Portekiz ve Yunanistan için $\mathrm{CO}_{2}$ emisyonundan sağlık harcamalarına doğru tek yönlü nedensellik ilişkisi olduğunu göstermektedir. Öte yandan Finlandiya, İsveç, İsviçre, İtalya, Hollanda, Polonya, Yunanistan, Avustralya, İspanya, Kanada ve Norveç ülkelerinde büyümeden sağlık harcamalarına doğru bir nedensellik ilişkisi bulunmuştur. Yazdi ve Khanalizadeh (2017) ise çalışmalarında MENA ülkeleri için 1995-2014 verilerini kullanarak sağlık harcamalarının çevre kirliliği ve ekonomik büyüme üzerindeki rolünü ARDL yöntemiyle araştırmışlardır. Çalışma sonuçlarına göre sağlık harcamaları, gelir ve çevre kirliliği arasında eşbütünleşme olduğu görülmüştür. Ayrıca ekonomik büyüme ve çevre kirliliğinin, sağlık harcaması üzerinde pozitif, anlamlı bir etkisi olduğu görülmüştür. 18 OECD ülkesi için yapılan çalışmada ise Wang vd. (2019), 1975-2017 döneminde sağlık harcamaları, ekonomik büyüme ve çevre kirliliği arasındaki ilişkiyi ARDL eşbütünleşme modeliyle incelemişlerdir. Çalışma sonuçları, tüm değişkenlerin arasında kısa dönemde ilişki olduğunu göstermektedir. Ek olarak, Almanya ve $A B D$ için sağılı harcamalarıyla ekonomik büyüme arasında, Kanada, Almanya ve $A B D$ için çevre kirliliği ve ekonomik büyüme arasında, Yeni Zelanda ve Norveç için sağlık harcamaları ile çevresel kirlilik arasında karşılıklı nedensellik ilişkisi olduğu görülmüştür. 
Mevcut literatür genel olarak değerlendirildiğinde, çevre kirliliğinin insan sağlığını olumsuz etkilediği ve bunun ekonomik büyümeyi yavaşlattığı söylenebilir. Literatüdeki çalışmaların çoğunluğu çevre kirliliği göstergesi olarak $\mathrm{CO}_{2}^{\prime}$ yi kullanmaktadır. Fakat insan sağlığı üzerinde partikül maddenin doğrudan bir etkiye sahip olduğu görülmektedir. Dolayısıyla sağlık harcamalarının da analize dahil edildiği çalışmada çevre kirliliği göstergesi olarak partikül maddenin kullanılması daha tutarlı sonuçlar verecektir.

\section{Veri ve Ekonometrik Metodoloji}

\subsection{Veri}

Bu çalışmada 1990-2018 dönemi için hava kirliliği ile sağlık harcamaları ve ekonomik büyüme arasındaki nedensellik ilişkisi seçilmiş BM ülkeleri özelinde ele alınmıştır. Ülke grubu Birleşmiş Milletler Taraflar Toplantılarında ülkeleri sınıflandıran EK-II'den seçilmiştir. EK-II ülkeleri, gelişmekte olan ülkelere yükümlülüklerini yerine getirmeleri için yardımcı olmanın yanında, uyum için gerekli mali kaynağı sağlamak ve teknoloji transferi için adımlar atmakla yükümlü ülkelerdir. Seçilmiş BM EK-II (ABD, Birleşik Krallık, Danimarka, Finlandiya, Fransa, Hollanda, İrlanda, İsveç, İsviçre, İtalya, İzlanda, Kanada, Norveç, Portekiz ve Yunanistan) ülkeleri için hava kirliliği ile sağlık harcamaları ve büyüme arasındaki ilişkiler panelin bütünü ve paneldeki birimler için Kónya (2006) panel nedensellik testleri ile araştırılmıştır. Bu çalışmada yararlanılan değişkenlere ilişkin bilgiler Tablo 1'de sunulmaktadır.

Tablo 1: Değişken Tanımları

\begin{tabular}{cccc}
\hline Değişken & Gösterge & Ölçüm & Kaynak \\
\hline Ekonomik Büyüme & BYM & Kişi başına ABD dolar & Dünya Bankası Veri Tabanı \\
Sağlık Harcamaları & SH & Kişi başına ABD dolar & OECD Stat Veri Tabanı \\
Hava Kirliliği & PM & Kişi başına kg & OECD Stat Veri Tabanı \\
\hline
\end{tabular}

Not: Yazarlar tarafından oluşturulmuştur.

Çalışmada, ekonomik büyümeyi temsilen kişi başına düşen dolar verisi kullanılmıştır. Sağıık harcamaları için OECD tarafından kişi başına düşen dolara dönüştürülmüş veri kullanılmıştır. Yine çalışmada hava kirliliği için ince partikül madde (PM2.5) verisi kişi başına düşen $\mathrm{kg}$ cinsinden kullanılmıştır. Ayrıca çalışmada incelenen BM EK-II ülkeleri, EK-I ülkelerinde yer alan ve geçiş ekonomisi olmayan OECD üyesi ülkeleri temsil etmektedir.

\subsection{Ekonometrik Metodoloji}

\subsubsection{Kónya (2006) Panel Nedensellik Testi}

Kónya (2006) nedensellik testi SUR modellerini temel alarak her bir kesit için kritik değerler bootsrap yöntemiyle tespit edilmektedir. Böylece nedensellik ilişkilerinin her bir birim için ayrı ayrı incelenebilmesine olanak sağlamaktadır. Öte yandan bu özellikler, yatay kesit bağımlıığının esnetilmesini sağlamaktadır. Ek olarak bu test ile durağan olmayan veya eşbütünleşik olmayan serilerle nedensellik ilişkisi incelenebilmektedir (Değirmenci ve Aydın, 2020:400). Modelde yatay kesit bağımlılı̆̆ olduğunda SUR ile elde edilen tahmincilerin kullanılmasının EKK tahmincilerine göre daha etkin sonuçlar vermesi bu testin sağladığı bir diğer avantajdır. Bu bağlamda, yatay kesit bağımlılığının bulunması halinde bu yöntemin tercih edilmesi daha etkin sonuçlar elde edilmesi açısından önemlidir (Kónya, 2006). 
Kónya panel nedensellik testinde aşağıdaki denklem sistemi kullanılmaktadır:

$$
\begin{gathered}
\mathrm{Y}_{1, \mathrm{t}}=\alpha_{1,1}+\sum_{i=1}^{k y_{1}} \beta_{1,1, i} Y_{1, t-i}+\sum_{i=1}^{k x_{1}} \phi_{1,1, i} X_{1, t-i}+\varepsilon_{1,1, t} \\
\mathrm{Y}_{2, \mathrm{t}}=\alpha_{1,2}+\sum_{i=1}^{k y_{1}} \beta_{1,2, i} Y_{2, t-i}+\sum_{i=1}^{k x_{1}} \phi_{1,2, i} X_{2, t-i}+\varepsilon_{1,2, t} \\
\mathrm{Y}_{\mathrm{N}, \mathrm{t}}=\alpha_{1, N}+\sum_{i=1}^{k y_{1}} \beta_{1, N, i} Y_{N, t-i}+\sum_{i=1}^{k x_{1}} \phi_{1, N, i} X_{N, t-i}+\varepsilon_{1, N, t}
\end{gathered}
$$

ve

$$
\begin{gathered}
X_{1, \mathrm{t}}=\alpha_{2,1}+\sum_{i=1}^{k y_{2}} \beta_{2,1, i} Y_{1, t-i}+\sum_{i=1}^{k x_{2}} \phi_{2,1, i} X_{1, t-i}+\varepsilon_{2,1, t} \\
X_{2, \mathrm{t}}=\alpha_{2,2}+\sum_{i=1}^{k y_{2}} \beta_{2,2, i} Y_{2, t-i}+\sum_{i=1}^{k x_{2}} \phi_{2,2, i} X_{2, t-i}+\varepsilon_{2,2, t} \\
X_{\mathrm{N}, \mathrm{t}}=\alpha_{2, N}+\sum_{i=1}^{k y_{2}} \beta_{2, N, i} Y_{N, t-i}+\sum_{i=1}^{k x_{2}} \phi_{2, N, i} X_{N, t-i}+\varepsilon_{2, N, t}
\end{gathered}
$$

Burada k bilgi kriterlerine göre belirlenen uygun gecikme uzunluğu olmak üzere $\mathrm{N}$ kesit birim sayısını ve $\mathrm{t}$ zaman boyutunu temsil etmektedir. Yukarıdaki eşitlik sistemi üzerinden nedensellik ilişkileri ve değişkenleri ile dört farklı şekilde ifade edilebilmektedir. Eğer bu değişkenlerin her ikisi de tüm birimler için sıfır ise $X$ ve $Y$ arasında herhangi bir nedensellik ilişkisi olmadığı anlamına gelirken, bu değişkenlerin her ikisinin de tüm birimler için sıfıra eşit olmadığı durumda değişkenler arasında çift yönlü bir nedensellik ilişkisi olduğu söylenebilmektedir. Ayrıca eğer tüm birimler için sıfıra eşit değilken tüm değişkenler için sıfıra eşit ise $X^{\prime}$ ten $Y^{\prime}$ ye doğru, tam tersi durumda $Y^{\prime}$ den $X^{\prime}$ doğru bir nedensellik ilişkisi olduğuna karar verilmektedir. Çalışmada, denklem sisteminin tahmininde optimal gecikme uzunluğu Kónya, 2006 çalışması dikkate alınarak; 1 ile 4 arasında Akaike ve Schwarz bilgi kriterlerini en düşük yapan gecikme kombinasyonu ile belirlenmiştir. 


\section{Ampirik Sonuçlar}

Bu çalışmada, seçili EK-II ülkeleri için hava kirliliği ile ekonomik büyüme ve sağlık harcamaları arasındaki dinamik ilişkiler panelin bütünü ve paneldeki birimler için Kónya (2006) panel nedensellik testi ile araştırılmıştır. Çalışmada, uygulanan Kónya (2006) panel nedensellik testinin yatay kesit bağımlıı̆̆ının olması durumunda EKK tahmin edicilerine kıyasla daha etkin sonuçlar verebilmesinden dolayı ilk olarak nedensellik analizinde kullanılan modeller üzerinden yatay kesit bağımlılığı araştırılmış ve elde edilen bulgular Tablo 2'de gösterilmektedir.

Tablo 2: Yatay Kesit Bağımlılığı Test Sonuçları

\begin{tabular}{cccc}
\hline Model & \multicolumn{3}{c}{ Test İstatistikleri } \\
\cline { 2 - 3 } & LM (Breusch,Pagan 1980) & CD-LM (Pesaran 2004) & CD (Pesaran 2004) \\
\hline BYM $\rightarrow$ PM & $651,206^{*}$ & $37,692^{*}$ & $20,073^{*}$ \\
PM $\rightarrow$ BYM & $2101,047^{*}$ & $137,740^{*}$ & $45,442^{*}$ \\
SH $\rightarrow$ BYM & $1633,270^{*}$ & $105,461^{*}$ & $34,836^{*}$ \\
BYM $\rightarrow$ SH & $1844,552^{*}$ & $120,040^{*}$ & $41,649^{*}$ \\
SH $\rightarrow$ PM & $983,009^{*}$ & $60,588^{*}$ & $27,552^{*}$ \\
$\mathrm{PM} \rightarrow$ SH & $226,542^{*}$ & $149,161^{*}$ & $47,277^{*}$
\end{tabular}

Not: ${ }^{*}$ temel hipotezin \%1 anlamlılık seviyesinde reddedildiğini göstermektedir. $\rightarrow$ nedensellik ilişkisinin incelendiği yönü göstermektedir.

Tablo 2' deki sonuçlar değerlendirildiğinde, nedensellik ilişkisinin araştırılmasında kullanılan tüm modellerde yatay kesit bağımlılığının olduğu görülmektedir. Yatay kesit bağımlılığının incelenmesinin ardından değişkenler arasındaki nedensellik ilişkileri Kónya (2006) nedensellik testi ile araştırılmış ve elde edilen bulgular EK kısmında gösterilmektedir.

Ülke bazlı sonuçlar hava kirliliği ve sağlık harcaması arasında, Finlandiya ve Kanada'da çift yönlü nedensellik ilişkisi elde edilirken, Yunanistan ve İzlanda'da hava kirliliğinden sağlık harcamalarına doğru bir nedensellik ilişkisi elde edilmiştir. Sağlık harcamaları ve büyüme arasındaki ilişkiler incelendiğinde ise Yunanistan ve İtalya'da sağlık harcamasından büyümeye doğru bir nedensellik ilişkisi olduğu görülürken, Danimarka, Finlandiya, İrlanda, Hollanda, İsviçre ve ABD'de büyümeden sağlık harcamasına doğru bir nedensellik ilişkisi olduğu görülmektedir. Son olarak ekonomik büyüme ve hava kirliliği arasındaki ilişkiler incelenmiş olup, Finlandiya ve Yunanistan'da çift yönlü bir ilişki elde edilirken, Norveç'te ekonomik büyümeden hava kirliliğine doğru bir nedensellik, Danimarka, İsviçre, ABD ve Kanada'da hava kirliliğinden büyümeye doğru bir nedensellik ilişkisi tespit edilmiştir. Panele ait sonuçlar ise EKII ülkelerinde hava kirliliğinden sağlık harcamalarına, hava kirliliğinden büyümeye ve büyümeden sağlık harcamasına doğru bir nedensellik ilişkisi olduğunu göstermektedir. 
Şekil 1: Panelin Bütününe ait Nedensellik Sonuçları Özeti

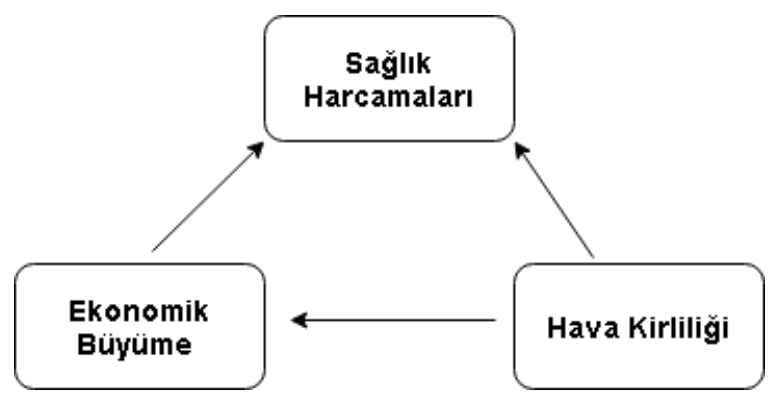

\section{Sonuç ve Değerlendirme}

Sera gazı emisyon değerlerindeki artışa, 1980'li yıllardaki Viyana Sözleşmesi ve Montreal Protokolü ile dikkat çekilse de küresel düzeyde en kapsamlı ortak tutum 1990'lı yıllardaki Birleşmiş Milletler Taraflar Toplantıları'nda gündeme gelmiştir. 1992 yılında Rio'daki toplantıyla usul ve esasları belirlenen ve 1995 'te Berlin'de birinci taraflar toplantısıyla başlayan süreç günümüze kadar yirmi beş toplantı ile devam etmiş ve bu yılın sonunda yirmi altıncısının yapılması kararlaştırılmıştır. Bu gelişmeler ışı̆̆ında özellikle hava kirliği ile ilgili farklı düzeyde istatistikler tutulmakta ve birçok araştırmada bu verilerden yararlanılmaktadır. Özellikle 1990'lı yıllardan itibaren hava kirliliğinin etkilerine ve ekonomik ve sosyal göstergelerle olan ilişkisine yönelik çok sayıda inceleme yapıldığı görülmektedir.

Bu çalışmada da emisyon azaltım sorumluluğu olan BM ülkeleri için hava kirliliği ile ekonomik büyüme ve sağlık harcamaları arasındaki nedensellik ilişkisi 1990-2018 dönemi kapsamında araştırılmıştır. Çalışmada hava kirliliği göstergesi olarak partikül madde (PM2.5) verisi kullanılmıştır. BM’nin insan sağlığını doğrudan etkilediğine dikkat çektiği partikül madde göstergesi kullanılarak, sağıık harcamaları ve ekonomik büyüme çerçevesinde konuyu inceleyen çalışmaların sayısı azdır. Çalışmalar daha çok iki gösterge arasındaki ilişkiyi incelemekte ve hava kirliliğini temsilen sera gazı emisyon değerlerini dikkate almaktadır. Bu çalışmanın bu yönüyle literatüre katkı sağlaması beklenmektedir.

Hava kirliliği, ekonomik büyüme ve sağıı harcaması arasındaki nedensellik ilişkisi panelin bütünü ve paneldeki birimler için Kónya (2006) panel nedensellik testi ile araştırılmıştır. Yatay kesit bağımlılığının olması durumunda EKK tahmin edicilerine kıyasla Kónya (2006) panel nedensellik testinin daha etkin sonuçlar verebilmesinden dolayı başlangıçta yatay kesit bağımlılığı incelenmiştir. Yatay kesit bağımlılığı bulunduktan sonra ilgili testler uygulanmıştır. Panele ait sonuçlar EK-II ülkelerinde hava kirliliğinden sağlık harcamalarına, hava kirliliğinden ekonomik büyümeye ve büyümeden sağlık harcamasına doğru bir nedensellik ilişkisi olduğunu göstermektedir. Hava kirliliğinden sağlık harcamasına doğru bulunan nedensellik ilişkisi Yazdi vd. (2014), Chaabouni vd. (2016), Zaidi ve Saidi (2018), Hao vd. (2018), Alimi vd. (2019), Şahin ve Durmuş (2019) ile Apergis vd. (2020)'nin bulgularını destekler niteliktedir. Ayrıca Shi vd. (2016)'a göre PM2.5 azaltımı halk sağığını olumlu olarak etkilemektedir. Bu sonuca göre dolaylı olarak sağlık harcamalarında bir azaltma görülmesi beklenebilir. Hava kirliliğinden ekonomik büyümeye doğru bulunan nedensellik ilişkisi Çevresel Kuznets Eğrisini geliştiren Grossman ve Krueger (1991)'ın ve ayrıca Zhu vd. (2012), Farhani ve Öztürk (2015), Doğan ve Türkekul (2016), Abdallh ve Abugamos (2017), Zaidi ve Saidi (2018), Amri vd. (2019), Destek 
ve Sinha (2020) ile Pata ve Aydın (2020)'ın bulgularını desteklemektedir. Ekonomik büyümeden sağlık harcamalarına doğru bulunan nedensellik ilişkisi ise Bakare ve Samni (2011), Mehrara ve Musai (2011), Halıcı-Tülüce vd. (2016), Chaabouni vd. (2016), Zaidi ve Saidi (2018) ile Dinçer ve Yuksel (2019)'in bulgularını destekler niteliktedir. Ayrıca bu ilişki Cylus vd. (2012), Khoshnevis Yazdi ve Khanalizadeh (2017) ve Dinçer ve Yüksel (2019)'in belirttiği gibi ülkelerin ekonomik anlamda büyüme gerçekleştirdikçe sağlık harcamalarına daha fazla önem verecekleri tezini de desteklemektedir.

Panelin bütününe ait hava kirliliği bulguları değerlendirildiğinde, sağlık harcamalarındaki ve ekonomik büyümedeki değişikliklerin nedenlerinden birinin hava kirliliğindeki değişiklikler olduğu söylenebilir. Buna göre toplum sağlığını iyileştirmek ve dolayısıyla bu alana yapılan harcamaları kontrol edebilmek için çevre kalitesinin dikkate alınması önemlidir. Öte yandan literatürde yaygın olarak partikül madde salınımındaki artıştan ekonomik büyüme sorumlu görülse de bu çalışmada ekonomik büyümeden hava kirliliğine doğru nedensellik ilişkisi bulunmamıştır. Ayrıca partikül madde azaltımı için ekonomik büyümenin dışında nüfus, kentleşme, trafik yoğunluğu ve endüstriyel yapı gibi birçok faktörün etkili olduğu tespit edilmiştir (Cheng vd. 2010; Han vd. 2014; Wang vd. 2017; Han ve Sun 2019). Ülke bazlı sonuçlardan özellikle Finlandiya ve Kanada'daki sağlık harcamaları-hava kirliliği yine Finlandiya ile Yunanistan'daki ekonomik büyüme-hava kirliliği arasındaki çift yönlü nedensellik ilişkisi dikkat çekicidir. Hava kirliliğinin hem sağlık harcamaları hem de ekonomik büyüme ile karşılıklı nedensellik ilişkisine ilişkin bulgular hava kirliliği konusunun etkilerini değerlendirmek adına oldukça önemlidir. 


\section{Kaynakça}

Abdallh, A. A., \& Abugamos, H. (2017), “A semi-parametric panel data analysis on the urbanisationcarbon emissions nexus for the MENA countries", Renewable And Sustainable Energy Reviews, 78, 13501356.

Alimi, O. Y., Ajide, K. B., \& Isola, W. A. (2019), "Environmental quality and health expenditure in ECOWAS", Environment, Development and Sustainability, 1-23.

Al-Mulali, U., Weng-Wai, C., Sheau-Ting, L., \& Mohammed, A. H. (2015), "Investigating the environmental Kuznets curve (EKC) hypothesis by utilizing the ecological footprint as an indicator of environmental degradation", Ecological Indicators, 48, 315-323.

Amri, F., Zaied, Y. B., \& Lahouel, B. B. (2019), “ICT, total factor productivity, and carbon dioxide emissions in Tunisia", Technological Forecasting and Social Change, 146, 212-217.

Apergis, N., Bhattacharya, M., \& Hadhri, W. (2020), "Health care expenditure and environmental pollution: a cross-country comparison across different income groups", Environmental Science and Pollution Research, 27(8), 8142-8156.

Atilgan, E., Kilic, D., \& Ertugrul, H. M. (2017), "The dynamic relationship between health expenditure and economic growth: is the health-led growth hypothesis valid for Turkey?", The European Journal of Health Economics, 18(5), 567-574.

Bakare, A. A., \& Olubokun, S. (2011), "Health care expenditure and economic growth in Nigeria: An empirical study", Journal of Emerging Trends in Economics and Management Sciences, 2(2), 83-87.

Chaabouni, S., Zghidi, N., \& Mbarek, M. B. (2016), “On the causal dynamics between CO2 emissions, health expenditures and economic growth", Sustainable Cities and Society, 22, 184-191.

Cheng, Y. H., \& Li, Y. S. (2010), "Influences of traffic emissions and meteorological conditions on ambient PM10 and PM2. 5 levels at a highway toll station", Aerosol and air quality research, 10(5), 456462.

Cylus, J., Mladovsky, P., \& McKee, M. (2012), "Is there a statistical relationship between economic crises and changes in government health expenditure growth? An analysis of twenty-four European countries", Health services research, 47(6), 2204-2224.

Çetin, M. ve Ecevit, E. (2010), "Sağlık Harcamalarının Ekonomik Büyüme Üzerindeki Etkisi: OECD Ülkeleri Üzerine Bir Panel Regresyon Analizi”, Doğuş Üniversitesi Dergisi, 11 (2), 166-182.

Değirmenci, T. ve Aydın, M. (2020), "Çevre Koruma Harcamaları ile Gelir Dağılımı ve Ekonomik Büyüme Arasındaki Dinamik illişkiler: Seçili OECD Ülkeleri için Panel Nedensellik Yaklaşımı", Sosyoekonomi, 28(46), 391-406.

Destek, M. A., \& Sarkodie, S. A. (2019), “Investigation of environmental Kuznets curve for ecological footprint: the role of energy and financial development", Science of the Total Environment, 650, 24832489.

Destek, M. A., \& Sinha, A. (2020), "Renewable, non-renewable energy consumption, economic growth, trade openness and ecological footprint: Evidence from organisation for economic Co-operation and development countries", Journal of Cleaner Production, 242, 118537.

Destek, M. A., Ulucak, R., \& Dogan, E. (2018), “Analyzing the environmental Kuznets curve for the EU countries: the role of ecological footprint", Environmental Science and Pollution Research, 25(29), 29387-29396.

Dickerson, P., Guerreiro, C., Keating, T., Nzioka, J. M., Chung, S. H., Reis, S., ... \& Hurley, F. (2019), "Air-Global Environment Outlook (GEO-6): Healthy Planet", Healthy People Chapter 5.", Global Environment Outlook (GEO-6): Healthy Planet, Healthy People. 
Dinçer, H., \& Yüksel, S. (2019), "Identifying the causality relationship between health expenditure and economic growth: an application on E7 countries", Journal of Health Systems and Policies, 1(1), 523.

Doğan, E., \& Türkekul, B. (2016), “ $\mathrm{CO}_{2}$ emissions, real output, energy consumption, trade, urbanization and financial development: testing the EKC hypothesis for the USA", Environmental Science and Pollution Research, 23(2), 1203-1213.

Dumrul, Y. (2019), "Sağlık harcamaları ve çevre kirliliği: ASEAN-5 ülkeleri üzerine bir panel veri analizi", IBAD Sosyal Bilimler Dergisi, 396-407.

Farhani, S., \& Ozturk, I. (2015), “Causal relationship between $\mathrm{CO}_{2}$ emissions, real GDP, energy consumption, financial development, trade openness, and urbanization in Tunisia", Environmental Science and Pollution Research, 22(20), 15663-15676.

Grossman, G. M., \& Krueger, A. B. (1991), “Environmental impacts of a North American free trade agreement (No. w3914). National Bureau of economic research.

Halıcı-Tülüce, N. S., Doğan, İ., \& Dumrul, C. (2016), “Is income relevant for health expenditure and economic growth nexus?", International journal of health economics and management, 16(1), 23-49.

Han, L., Zhou, W., Li, W., \& Li, L. (2014), “Impact of urbanization level on urban air quality: A case of fine particles (PM2. 5) in Chinese cities", Environmental Pollution, 194, 163-170.

Han, S., \& Sun, B. (2019), "Impact of population density on PM2. 5 concentrations: A case study in Shanghai, China", Sustainability, 11(7), 1968.

Hao, Y., Liu, S., Lu, Z. N., Huang, J., \& Zhao, M. (2018), "The impact of environmental pollution on public health expenditure: dynamic panel analysis based on Chinese provincial data", Environmental Science and Pollution Research, 25(19), 18853-18865.

Hassan, S. T., Baloch, M. A., Mahmood, N., \& Zhang, J. (2019), "Linking economic growth and ecological footprint through human capital and biocapacity", Sustainable Cities and Society, 47, 101516.

Hassan, S. T., Xia, E., Khan, N. H., \& Shah, S. M. A. (2019), “Economic growth, natural resources, and ecological footprints: evidence from Pakistan", Environmental Science and Pollution Research, 26(3), 2929-2938.

Khoshnevis Yazdi, S., \& Khanalizadeh, B. (2017), "Air pollution, economic growth and health care expenditure", Economic research-Ekonomska istraživanja, 30(1), 1181-1190.

Kónya, L. (2006), "Exports and growth: Granger causality analysis on OECD countries with a panel data approach", Economic Modelling, 23(6), 978-992.

Lucas, P., Hedden, S., van Vuuren, D., Calvin, K. V., Chung, S. H., Harfoot, M., ... \& Hurley, F. (2019), Future Developments Without Targeted Policies-Global Environment Outlook (GEO-6): Healthy Planet, Healthy People Chapter 21", Global Environment Outlook (GEO-6): Healthy Planet, Healthy People.

Mehrara, M., \& Musai, M. (2011), "The causality between health expenditure and economic growth in Iran", Int. J. Eco. Res, 2(4), 13-19.

Organisation for Economic Co-operation and Development (OECD) Data (2020), https://data.oecd.org/air/air-pollution-exposure.htm, (Erişim: 05.10.2020).

Organisation for Economic Co-operation and Development (OECD) Statistics (2020, December 9), "Emissions of air pollutants", https://stats.oecd.org/, (Erişim:21.10.2020).

Organisation for Economic Co-operation and Development (OECD) Statistics (2020, Nowember), "Health expenditure and financing", https://stats.oecd.org/, (Erişim:21.10.2020).

Pata, U. K., \& Aydin, M. (2020), "Testing the EKC hypothesis for the top six hydropower energyconsuming countries: Evidence from Fourier Bootstrap ARDL procedure", Journal of Cleaner Production, 121699. 
Piabuo, S. M., \& Tieguhong, J. C. (2017), "Health expenditure and economic growth-a review of the literature and an analysis between the economic community for central African states (CEMAC) and selected African countries", Health economics review, 7(1), 1-13.

Ouyang, X., Shao, Q., Zhu, X., He, Q., Xiang, C., \& Wei, G. (2019), "Environmental regulation, economic growth and air pollution: Panel threshold analysis for OECD countries", Science of the total environment, 657, 234-241.

Shi, L., Zanobetti, A., Kloog, I., Coull, B. A., Koutrakis, P., Melly, S. J., \& Schwartz, J. D. (2016), "Lowconcentration PM2. 5 and mortality: estimating acute and chronic effects in a population-based study", Environmental health perspectives, 124(1), 46-52.

Şahin, D., ve Durmuş, S. (2019), “OECD Ülkelerinde Ekonomik Büyüme Ve Çevre Kirliliğinin Sağlık Harcamaları Üzerine Etkisinin Analizi", Finans Politik \& Ekonomik Yorumlar, 56(647), 185-201.

Wang, C. M., Hsueh, H. P., Li, F., \& Wu, C. F. (2019), "Bootstrap ARDL on Health Expenditure, $\mathrm{CO}_{2}$ Emissions, and GDP Growth Relationship for 18 OECD Countries", Frontiers in Public Health, 7,324.

Wang, S., Zhou, C., Wang, Z., Feng, K., \& Hubacek, K. (2017), "The characteristics and drivers of fine particulate matter (PM2. 5) distribution in China", Journal of Cleaner Production, 142, 1800-1809.

Wang, Y., Zhang, X., Kubota, J., Zhu, X., \& Lu, G. (2015), "A semi-parametric panel data analysis on the urbanization-carbon emissions nexus for OECD countries", Renewable and Sustainable Energy Reviews, 48, 704-709.

World Bank Data (2020), "GDP per capita (current US\$)", https://data.worldbank.org/indicator/NY.GDP.PCAP.CD, (Erişim: 12.10.2020).

World Health Organization (2021), "Air pollution", https://www.who.int/airpollution/en/, (Erişim: 12.10.2020).

Wu, J., Zheng, H., Zhe, F., Xie, W., \& Song, J. (2018), "Study on the relationship between urbanization and fine particulate matter $\left(\mathrm{PM}_{2.5}\right)$ concentration and its implication in China", Journal of Cleaner Production, 182, 872-882.

Yazdi, S., Zahra, T., \& Nikos, M. (2014), "Public healthcare expenditure and environmental quality in Iran", Recent Advances in Applied Economics, (233).

Zaidi, S., \& Saidi, K. (2018), "Environmental pollution, health expenditure and economic growth in the Sub-Saharan Africa countries: Panel ARDL approach", Sustainable cities and society, 41, 833-840.

Zhu, H. M., You, W. H., \& Zeng, Z. F. (2012), “Urbanization and CO2 emissions: A semi-parametric panel data analysis", Economics Letters, 117(3), 848-850. 


\section{Ekler}

Aşağıdaki tablolarda, $*, * *$, ve ${ }^{* * *}$ sırasıyla $\% 1, \% 5$ ve $\% 10$ anlamlılık düzeyinde temel hipotezinin reddedildiğini göstermektedir. Uygun gecikme uzunluğu Akaike kriteri baz alınarak 1 olarak belirlenmiştir. Bootstrap döngüsü 10.000 tekrarda gerçekleştirilmiştir.

Tablo 3: Kónya Panel Nedensellik Testi Sonuçları: Hava Kirliliği-Sağlık Harcamaları

\section{$H_{0}$ : Hava kirliliği, Sağlık harcamalarının nedeni değildir.}

\begin{tabular}{lcccc}
\hline Bootstrap Kritik Değerler & \multicolumn{3}{c}{} \\
\hline Ülkeler & Wald isst. & \%1 & \%5 & \%10 \\
\hline Danimarka & 0,234 & 6,284 & 3,396 & 2,375 \\
Finlandiya & $8,319^{* *}$ & 13,801 & 8,208 & 6,386 \\
Fransa & 8,357 & 31,901 & 21,407 & 16,477 \\
Yunanistan & $8,637^{* * *}$ & 15,702 & 10,402 & 8,096 \\
İzlanda & $21,458^{* *}$ & 27,213 & 18,203 & 14,548 \\
İrlanda & 15,068 & 28,251 & 20,696 & 16,933 \\
İtalya & 0,629 & 12,881 & 6,888 & 5,063 \\
Hollanda & 7,916 & 24,107 & 15,749 & 13,553 \\
Norveç & 4,839 & 22,295 & 11,746 & 8,738 \\
Portekiz & 1,991 & 16,540 & 8,529 & 5,858 \\
İsveç & 8,825 & 41,044 & 29,374 & 24,276 \\
İsviçre & 0,050 & 3,173 & 1,788 & 1,331 \\
Birleşik Krallık & 7,570 & 25,155 & 18,437 & 15,342 \\
ABD & 1,925 & 31,025 & 20,875 & 14,964 \\
Kanada & $9,489 *$ & 9,167 & 5,910 & 4,565 \\
\hline Panel & Fisher İst. & Olasılık Değ. & & \\
\hline
\end{tabular}

Tablo 4: Kónya Panel Nedensellik Testi Sonuçları: Hava Kirliliği-Sağlık Harcamaları

$H_{0}$ : Sağlık harcamaları, Hava kirliliğinin nedeni değildir.

\section{Bootstrap Kritik Değerler}

\begin{tabular}{lcccc}
\hline Ülkeler & Wald İst. & \%1 & \%5 & \%10 \\
\hline Danimarka & 13,006 & 33,472 & 23,043 & 20,758 \\
Finlandiya & $24,882^{* *}$ & 25,256 & 19,552 & 16,871 \\
Fransa & 2,268 & 83,243 & 53,944 & 43,277 \\
Yunanistan & 8,739 & 11,880 & 10,006 & 8,993 \\
İzlanda & 4,737 & 12,734 & 9,074 & 7,572 \\
İrlanda & 4,497 & 23,318 & 15,823 & 13,519 \\
İtalya & 8,013 & 38,446 & 23,844 & 18,931 \\
Hollanda & 2,025 & 6,423 & 4,429 & 3,473 \\
Norveç & 17,991 & 49,948 & 39,241 & 33,648 \\
Portekiz & 7,304 & 33,289 & 25,162 & 21,889 \\
İsveç & 0,679 & 23,235 & 15,420 & 12,706 \\
İsviçre & 15,092 & 39,294 & 28,661 & 23,623 \\
Birleşik Krallık & 0,536 & 25,202 & 18,462 & 15,008 \\
ABD & 4,297 & 43,103 & 32,438 & 27,834 \\
Kanada & $2,246 * * *$ & 4,880 & 2,993 & 1,936 \\
\hline Panel & Fisher İst. & Olasılık Değ. & & \\
& 29,599 & 0,486 & & \\
\hline
\end{tabular}


Tablo 5: Kónya Panel Nedensellik Testi Sonuçları: Sağlık Harcamaları-Ekonomik Büyüme

Ho: Sağlık harcamaları, Ekonomik Büyümenin nedeni değildir.

\begin{tabular}{lcccc}
\hline Bootstrap Kritik Değerler & \multicolumn{3}{c}{} \\
\hline Ülkeler & Wald İst. & \%1 & \%5 & \%10 \\
\hline Danimarka & 3,326 & 35,675 & 26,625 & 20,831 \\
Finlandiya & 0,268 & 32,897 & 24,458 & 19,687 \\
Fransa & 2,594 & 55,092 & 40,393 & 34,150 \\
Yunanistan & $12,178^{*}$ & 8,991 & 4,720 & 3,218 \\
İzlanda & 24,688 & 159,536 & 114,664 & 97,725 \\
İrlanda & 0,213 & 26,768 & 15,733 & 12,187 \\
İtalya & $7,513 *$ & 4,586 & 2,440 & 1,748 \\
Hollanda & 0,015 & 44,121 & 30,081 & 25,157 \\
Norveç & 2,031 & 6,267 & 4,414 & 3,145 \\
Portekiz & 0,105 & 38,639 & 29,308 & 23,075 \\
İsveç & 0,235 & 53,899 & 36,636 & 31,376 \\
İsviçre & 6,763 & 62,956 & 47,724 & 40,318 \\
Birleşik Krallık & 0,130 & 73,308 & 50,825 & 39,356 \\
ABD & 5,916 & 52,225 & 36,355 & 30,134 \\
Kanada & 10,411 & 86,122 & 66,689 & 57,000 \\
\hline Panel & Fisher İst. & Olasılık Değ. & & \\
\end{tabular}

Tablo 6: Kónya Panel Nedensellik Testi Sonuçları: Sağlık Harcamaları-Ekonomik Büyüme

\begin{tabular}{|c|c|c|c|c|}
\hline \multicolumn{5}{|c|}{$\mathrm{H}_{0}$ :Ekonomik Büyüme, Sağlık Harcamalarının nedeni değildir. } \\
\hline \multicolumn{5}{|c|}{ Bootstrap Kritik Değerler } \\
\hline Ülkeler & Wald İst. & \%1 & $\% 5$ & \%10 \\
\hline Danimarka & $16,363^{* *}$ & 21,217 & 14,855 & 12,058 \\
\hline Finlandiya & $39,439 * *$ & 49,267 & 37,043 & 32,573 \\
\hline Fransa & 1,477 & 11,774 & 8,634 & 7,119 \\
\hline Yunanistan & 17,104 & 45,855 & 32,581 & 27,704 \\
\hline İzlanda & 0,104 & 86,609 & 59,698 & 49,393 \\
\hline İrlanda & $68,012^{*}$ & 32,699 & 23,789 & 20,277 \\
\hline İtalya & 3,126 & 20,025 & 14,890 & 12,799 \\
\hline Hollanda & $44,250 * *$ & 49,698 & 37,281 & 32,518 \\
\hline Norveç & 18,365 & 30,381 & 22,642 & 19,761 \\
\hline Portekiz & 2,775 & 29,246 & 19,553 & 16,011 \\
\hline İsveç & 7,909 & 28,369 & 18,906 & 15,391 \\
\hline İsviçre & $20,550 * * *$ & 30,617 & 20,791 & 16,461 \\
\hline Birleşik Krallık & 4,532 & 29,993 & 21,379 & 17,711 \\
\hline$A B D$ & $8,841 * * *$ & 13,597 & 10,155 & 8,512 \\
\hline Kanada & 0,745 & 38,119 & 20,563 & 16,321 \\
\hline Panel & $\begin{array}{l}\text { Fisher İst. } \\
56,907^{*}\end{array}$ & $\begin{array}{c}\text { Olasıllık Değ. } \\
0,002\end{array}$ & & \\
\hline
\end{tabular}


Tablo 7: Kónya Panel Nedensellik Testi Sonuçları: Ekonomik Büyüme - Hava Kirliliği

$\mathrm{H}_{0}$ :Ekonomik Büyüme, Hava Kirliliğinin nedeni değildir.

Bootstrap Kritik Değerler

\begin{tabular}{lcccc}
\hline Ülkeler & Wald ist. & \%1 & \%5 & \%10 \\
\hline Danimarka & 1,233 & 14,332 & 9,817 & 7,639 \\
Finlandiya & $6,275^{* * *}$ & 9,753 & 6,338 & 5,041 \\
Fransa & 47,288 & 98,307 & 75,605 & 63,710 \\
Yunanistan & $5,154^{*}$ & 4,571 & 3,278 & 2,715 \\
İzlanda & 1,248 & 4,942 & 3,284 & 2,368 \\
İrlanda & 2,882 & 34,214 & 19,283 & 15,067 \\
İtalya & 0,435 & 20,771 & 14,108 & 10,952 \\
Hollanda & 0,014 & 4,896 & 2,765 & 1,837 \\
Norveç & $6,858^{* *}$ & 8,473 & 6,751 & 5,773 \\
Portekiz & 4,711 & 9,789 & 7,071 & 5,909 \\
İsveç & 0,085 & 21,720 & 15,418 & 11,852 \\
İsviçre & 2,483 & 19,318 & 12,288 & 9,214 \\
Birleşik Krallık & 0,989 & 52,868 & 36,892 & 28,652 \\
ABD & 3,916 & 60,655 & 31,925 & 24,700 \\
Kanada & 1,458 & 6,747 & 3,735 & 2,362 \\
\hline Panel & Fisher İst. & Olasılı Değ. & & \\
\hline
\end{tabular}

Tablo 8: Kónya Panel Nedensellik Testi Sonuçları: Ekonomik Büyüme - Hava Kirliliği

\begin{tabular}{|c|c|c|c|c|}
\hline \multicolumn{5}{|c|}{$\mathrm{H}_{0}$ :Hava Kirliliği, Ekonomik Büyümenin nedeni değildir. } \\
\hline \multicolumn{5}{|c|}{ Bootstrap Kritik Değerler } \\
\hline Ülkeler & Wald İst. & $\% 1$ & $\% 5$ & \%10 \\
\hline Danimarka & $31,763^{* *}$ & 35,329 & 24,397 & 19,740 \\
\hline Finlandiya & $84,774^{*}$ & 65,189 & 46,859 & 39,625 \\
\hline Fransa & 2,018 & 134,015 & 86,588 & 73,351 \\
\hline Yunanistan & $15,179 * * *$ & 26,344 & 18,714 & 15,013 \\
\hline İzlanda & 1,552 & 12,686 & 6,602 & 4,690 \\
\hline İrlanda & 0,188 & 26,981 & 17,361 & 14,333 \\
\hline İtalya & 2,583 & 10,631 & 6,259 & 4,684 \\
\hline Hollanda & 24,385 & 71,942 & 55,093 & 45,326 \\
\hline Norveç & 3,042 & 13,627 & 9,938 & 7,987 \\
\hline Portekiz & 1,833 & 7,359 & 4,370 & 3,023 \\
\hline İsveç & 42,315 & 117,660 & 81,595 & 69,312 \\
\hline İsviçre & $27,543^{* *}$ & 36,225 & 25,667 & 21,638 \\
\hline Birleşik Krallık & 64,944 & 111,923 & 78,367 & 65,279 \\
\hline$A B D$ & $42,815^{* *}$ & 65,156 & 41,514 & 30,624 \\
\hline Kanada & $16,317^{*}$ & 15,745 & 10,442 & 8,983 \\
\hline Panel & $\begin{array}{c}\text { Fisher İst. } \\
63,576^{*}\end{array}$ & $\begin{array}{c}\text { Olasilık Değ. } \\
0,000\end{array}$ & & \\
\hline
\end{tabular}




\section{Extended Summary}

\section{The Relationship between Air Pollution, Health Expenditures and Economic Growth in UN Countries with Emission Reduction Responsibility}

Air pollution is one of the most common types of environmental pollution. Because air pollution has direct adverse effects on both living and non-living life. Today, millions of people in all countries lose their lives or face significant health problems due to air pollution. Especially in developing and underdeveloped countries, these problems are getting deeper and reveal irreversible situations. For this reason, the causes and effects of air pollution should be determined well, and permanent solutions should be produced to eliminate this problem. Air pollution can occur on a regional, national and global scale. However, it should be noted right away that factors such as the increase in the human population, technological developments, and accordingly the increase in human needs have carried the dimensions and effects of air pollution from regional to national, from national to global scale over time. Therefore, establishing cooperation between the countries for the solution of this problem came to the fore, and various agreements were made. The effects of air pollution on economic and social life should not be ignored. Air pollution, which restricts social life and economic activities, causes psychological problems to deepen and spread, disrupts the ecological balance, complicates the fight against climate change, affects green areas, agricultural areas, waters, and living things living in water, on the other hand, reduces productivity in industrial areas. Accordingly, those working in industries that emit gases and particles that cause air pollution are reduced because they are affected by these gases. Although the increase in air pollution in the world started to be mentioned after the second half of the 20th century, after the 1980s, the search for solutions to this problem increased with multilateral agreements. The meetings held under the leadership of the United Nations in the 1990s brought along new discussions on the fundamental acceptance and solution of the problem. In this process, the effort to reduce greenhouse gas emissions, especially by the use of fossil fuels, became the agenda of the next meetings and was also the subject of examination in many researches. In this context, it can be said that emissions associated with economic growth and resulting from the use of fossil fuels cause global climate change and consequently negatively affect human health. This has become the focus of many researchers and policymakers. The fact that the United Nations Annex-II countries had to reduce their greenhouse gas emission values after the 1997 Kyoto Protocol made cleaner production sources mandatory, especially in the field of energy. However, many countries have sought a cleaner and more environmentally friendly production model. While the countries that can achieve sufficient transformation throughout the process can reduce their emission values over the years, the countries that cannot achieve this have not been able to reduce or the amount of reduction has not reached a sufficient level. Because reduction has a high economic cost. For this reason, an important part of air pollution research is also associated with economic growth or development. In some studies, the effect of air pollution on human health is discussed and the relationship between air pollution and health expenditures is examined.

The fact that air pollution has such effects is frequently emphasized in scientific studies, and the relationship between air pollution and economic and social indicators is examined in many studies. In this study, the causality relationship between air pollution, health expenditures, and economic growth for the period of 1990-2018 are discussed in the selected UN countries (USA, UK, Denmark, Finland, France, Netherlands, Ireland, Sweden, Switzerland, Italy, Iceland, Canada, Norway, Portugal, and Greece). The country group has been selected from Annex-II, which classifies countries at the United Nations Conferences of the Parties. Annex-II countries are obliged to provide the necessary financial resources for harmonization and to take steps for technology transfer, as well as helping developing countries to fulfill their obligations.

When the existing literature is evaluated in general, it can be said that environmental pollution affects human health negatively and this slows down economic growth. Most of the studies in the literature use $\mathrm{CO}_{2}$ as an environmental pollution indicator. However, particulate matter appears to have a direct effect on human health. Therefore, the use of particulate matter as an indicator of environmental pollution in the study, in which health expenditures are also included in the analysis, will give more consistent results. The results of the study show that there is a causal relationship between economic growth to health expenditures, air pollution to health expenditures, and air pollution to economic growth. Among the findings of the study, the bidirectional causality relationship between health expenditures-air pollution in Finland and Canada, and economic growth-air pollution in Finland and Greece is also remarkable. The findings regarding the mutual causality relationship of air pollution with both health expenditures and economic growth are very important in order to evaluate the effects of air pollution. A causal relationship from air pollution to health expenditures supports the studies of Yazdi et al. (2014), Chaabouni et al. (2016), Zaidi and Saidi (2018), Alimi et al. (2019), and Apergis et al. (2020) in terms of the results obtained. A causal relationship from air pollution to economic growth supports the studies of Zhu et al. (2012), Farhani and Ozturk (2015), Dogan and Turkekul (2016), Abdallh and Abugamos (2017), Zaidi and Saidi (2018), Amri et al. (2019), Destek and Sinha (2020) and Pata and Aydın(2020) in terms of the results obtained. On the other hand, A causal relationship from economic growth to health expenditures supports the studies of Bakare and Samni (2011), Mehrara and Musai (2011), HalıclTülüce et al. (2016), Chaabouni et al. (2016), Zaidi and Saidi (2018) and Dinçer and Yuksel (2019) in terms of the results obtained. Both similar studies in the literature and the findings obtained in this study show a causal relationship between the three variables. The different causality relationships between the variables in the country may result from the differences in the developed levels, national legislation, economic and social structures of the countries, and many other national indicators. 